\title{
Bus Stop Consolidation Analysis for Puerto Rico's Metropolitan Bus Authority
}

Wilfredo R. Cordero, M.E.C.E. ${ }^{1}$, Ivette Cruzado, Ph.D. ${ }^{2}$, Benjamín Colucci, Ph.D., ${ }^{1}$, and Didier Valdés, Ph.D. ${ }^{2}$

${ }^{1}$ University of Puerto Rico at Mayagüez, Puerto Rico, wilfredo.cordero@upr.edu, benjamin.colucci1@upr.edu

2Ivette.cruzado@upr.edu,dider.valdes@upr.edu

\begin{abstract}
Technology has a deep impact on everyday life of most people in today's society. Informatics is a basic element of this evolution and is. therefore getting more and more important for education, too. To introduce children of all ages to different topics of informatics, the Regional Educational Competence Centre for Informatics in Carinthia, Austria, organized a four-week lasting Informatics-Lab. During their holidays in July 2014, children were able to visit our university, participate in workshops and get a first or a deeper impression of topics like encryption, operating systems, networks or modelling. What distinguished this project from other labs was that the children learned from trainees aged between 16 and 19 years as well as from their peers. Furthermore, trainees and visitors developed new teaching material on their own. This was an important element of the project as it considered different learning concepts like learning by teaching. The lab got positive feedback from both, children and parents. A pre-post comparison showed that the project had positive effects on the interest as well as on the attitude towards informatics. This paper gives some background information about the learning concept and an overview of the activities and stations. Furthermore, the results from an empirical survey are presented.

Keywords-- Learning lab; informatics; primary education
\end{abstract}

Digital Object Identifier

(DOI):http://dx.doi.org/10.18687/LACCEI2016.1.1.244

ISBN: 978-0-9822896-9-3

ISSN: 2414-6390

$14^{\text {th }}$ LACCEI International Multi-Conference for Engineering, Education, and Technology: "Engineering Innovations for Global Sustainability", 20-22 July 2016, San José, Costa Rica. 


\title{
Bus Stop Consolidation Analysis for Puerto Rico’s Metropolitan Bus Authority
}

\author{
Wilfredo R. Cordero, M.E.C.E. ${ }^{1}$, Ivette Cruzado, Ph.D. ${ }^{2}$, Benjamín Colucci, Ph.D., ${ }^{1}$, and Didier Valdés, Ph.D. ${ }^{2}$ \\ ${ }^{1}$ University of Puerto Rico at Mayagüez, Puerto Rico, wilfredo.cordero@upr.edu, benjamin.colucci1@upr.edu \\ 2ivette.cruzado@upr.edu, dider.valdes@upr.edu
}

\begin{abstract}
Transit planning in the San Juan Metropolitan Area (SJMA) of the Commonwealth of Puerto Rico, has been a challenge because of its low patronage. Several reasons for the lack of patronage among the community are urban sprawl, excess of incentives for private transportation, easy acquisition of a private motor vehicle, relative low prices of gas fuel, and laws and policies that prioritize the use of private vehicles, among others. The Metropolitan Bus Authority (MBA) of Puerto Rico is aware of these challenges and has been identifying inefficiencies that could foster a low patronage of the transit system. The results of a study performed in 2014 at the University of Puerto Rico at Mayagüez. (UPRM) describe the actual conditions and accessibility of many of the MBA bus stops and compliance of the sidewalks and shelters within the American with Disabilities Act (ADA) requirements. The conclusions of the study indicate that many bus stops show little or no ridership, possibly due to ineffective placement of bus stops. To address this problem, two methodologies were applied in order to identify which bus stops could be consolidated or eliminated from MBA's Route 5. The first methodology analyzes the benefit and cost of removing a bus stop by calculating a benefit-cost ratio for each stop. The second methodology consists of a four-step process where the main purpose is to assign each stop a class of importance from $A$ (being the most important) to $F$ (being the least important). Ultimately, the benefit-cost ratio method suggested 32 stops be removed while the four-step process method recommended 20 stops be removed. A combination of both methodologies is provided, resulting in a total of 36 out of 98 bus stops to be eliminated. Both methods are easily implemented and can be considered as low cost solutions for the MBA.

Keywords—bus stop consolidation
\end{abstract}

\section{INTRODUCTION}

The organization and planning of transportation systems are vital factors for the economic and social development of cities around the world. A city with good planning and operation of its transportation system can move goods and people efficiently, quickly, and inexpensively, thus contributing to economic development. People began living in cities to minimize travel time and maximize all potential business and commercial exchanges. However, in some cities this concept has disappeared due to urban sprawl and lack of planning. Scattered urban areas are mainly connected by roads, thus giving higher priority and more attention to the use of private cars than any other method of transportation. Therefore, the road system focuses on providing greater benefits to private transport.

Despite all efforts to guide and convince people of the advantages of using public transport or other non-motorized means for commuter and other trips, private transport is still preferred. There are many reasons that can explain this behavior, such as the convenience and flexibility that people have by traveling in their own private vehicles or the inefficiency and/or lack of a truly accessible public transport system that can adequately meet the needs of users. For this reason, it is imperative for transportation related government agencies to provide a public transport system that can be considered organized, reliable, and efficient.

Buses are among the many options offered by a public transport system. Bus systems have been, historically, a solution to the problem of city transportation. But for such a system to be efficient and convenient for users, it must have a high degree of organization and maintenance. For transit services, it is important that all lines, networks, stations and stops be well planned and organized according to local needs. This means the transportation system must have a good management system, provide a feasible schedule in which the operator can meet and users can trust, and an infrastructure of stops and stations where users feel safe.

Inside the area of a line's infrastructure, bus stops are one of the principal elements because they represent the link between users and buses [1]. A bus stop could be analyzed in several areas of interest. These areas of interest are, but not limited to: landing areas, shelter conditions, information features, traffic and pedestrian safety issues, proper identification, and location. The location of a bus stop should be one of the top priorities to any transit agency; if excessively short distances exist between bus stops, the bus will have a longer cycle time and through passengers will experience elongated riding time. On the contrary, if bus stops are located too far apart, people may not be willing to walk such long distances.

There are many guidelines in the United States (US) that provide several optimal spacing options between bus stops. A recent study found that 95 of 111 US transit agencies have stop spacing guidelines, with about one-half recommending spacing distances between 200 and $270 \mathrm{~m}$ (six to eight stops per mile) and even closer spacing in business districts. In contrast, in places of northern Europe where transit has a much greater market, the average bus stop spacing is between 400 and $530 \mathrm{~m} \mathrm{[2].} \mathrm{By} \mathrm{providing} \mathrm{more} \mathrm{space} \mathrm{between} \mathrm{stops,} \mathrm{shorter}$ cycle times are accumulated, and a decrease in through passenger riding times can be seen. Transit agencies must develop new standards and tools with simple terminologies and implementation methods to know which bus stops could be removed and/or consolidated.

Digital Object Identifier (DOI): http://dx.doi.org/10.18687/LACCEI2016.1.1.244 ISBN: 978-0-9822896-9-3

ISSN: 2414-6390

14 ${ }^{\text {th }}$ LACCEI International Multi-Conference for Engineering, Education, and Technology: "Engineering Innovations for Global Sustainability", 20-22 July 2016, San José, Costa Rica. 
The Metropolitan Bus Authority (MBA) is the major public transit agency in the Commonwealth of Puerto Rico; it consists of 30 bus routes and serves 30,000 users annually. MBA Route 5 is one of the top 5 routes in terms of ridership that provides service to main neighborhoods and sectors within SJMA namely Santurce, Isla Verde, Luis Muñoz Marín International Airport, and the Los Angeles sector; it has a length of approximately 25 miles in both directions and has 98 bus stops, as shown in Fig. 1. Route 5 serves urban and residential areas and has a daily average ridership of 3,350 persons per day.

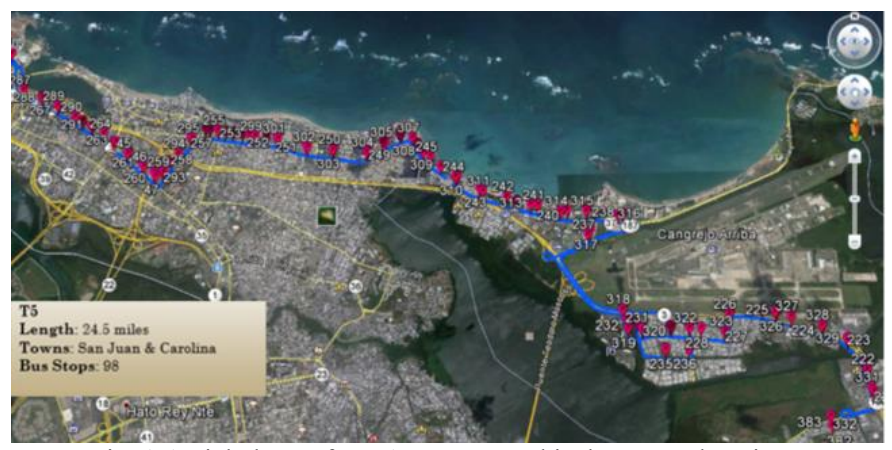

Fig. 1 Aerial photo of MBA Route 5 and its bus stops locations.

\section{OBJECTIVES}

This project aimed to develop a standardized process for choosing which bus stops on MBA Route 5 should be consolidated (i.e., eliminated). In order to determine this, the sponsorship of passengers in each one of the stops was considered. Also, the land use around current bus stops and other possible places were identified as well as the accessibility of sidewalks. In order to accomplish the main goal of the research, the following objectives were established:

- Study actual procedures and methods for bus stop consolidation

- Identify previous studies dedicated to the performance of bus systems and bus stops

- Create a tool to evaluate each bus stop on Route 5 and recommend which stops should be eliminated or consolidated

\section{LITERATURE REVIEW}

The efforts for finding optimal spacing between bus stops have provided complex and simple approaches. By removing unnecessary stops, buses will have reduced running times, which can lead to higher frequencies and/or fewer buses on a route [3]. Stewart and El-Geneidy [3] indicate that current analysis and investigations, regarding optimal spacing or consolidation of bus stops, are too complex for transit agencies to implement.

Several approaches for bus stop consolidation were performed by Furth and Rahbee [2]; these authors developed a complex dynamic programming algorithm to find the least expensive solution to stop location. The study used a discrete approach to model the impacts of changing bus-stop spacing on a bus route. This research establishes and defines three main societal impacts (riding time, operating costs, and walking time) based on the benefit and cost of removing or consolidating a bus stop. The riding time of a bus is affected when more frequent stops are present because through passengers spend more time on the bus. Operating costs increase with large amounts of stops because these stops result in an increase in bus cycle time. On the other hand, passenger walk time decreases when stops are placed in closer proximities to one another.

El-Geneidy et al [4] analyzed the change in passenger activity and operating performance after the implementation of bus stop consolidation in Oregon. The result of the study indicates that, after the consolidation of bus stops, passenger activity increased and a reduction in running time was found. In comparison, $\mathrm{Li}$ and Bertini [5], utilizing a less complex method, developed a stop spacing model that considered the passenger access cost and in-vehicle passenger stopping cost to minimize the total cost. The authors established that delays for through passengers and shorter walking times parallel to the route are both among the impacts of frequent stops.

The Washington Metropolitan Area Transit Authority [6] performed their own bus stop consolidation analysis using four different combinations of two aspects of time savings per removed bus stop along the line (10 and 20 seconds) and implementation of new spacing standards (4 or 5 stops per mile). Moura et al. [7] analyze an optimal bus stop location using a sequentially applied two-stage model. The first stage of the model suggests to strategically locate bus stops in the entire public transport system on a macroscopic scale while the social cost of the network was minimized. The second stage is used as a tactical approach to consider the previously obtained macroscopic solution to microscopically locate the stops along specific urban places and, at the same time, maximize the commercial speed of the public transport service.

Recent approaches are shown by Stewart and El-Geneidy [3] and Wagner and Bertini[8]; the first described a 5-step process to assign importance to the bus stops from $\mathrm{A}$ to $\mathrm{F}$ and the second described a methodology that calculates the benefit and cost of removing a bus stop to obtain a benefit-cost ratio.

\section{RESEARCH METHODOLOGY}

The methodology developed for this study is based upon two different studies about consolidation of bus stops. The first one was proposed by Wagner and Bertini [8], in which was developed a benefit-cost ratio $(\mathrm{B} / \mathrm{C})$ for each bus stop under consideration. Although one of the limitations of this methodology is that it should be applied to a grid of small blocks, it was still selected because many areas along Route 5 did fulfill this requirement. The second methodology considered was developed by Stewart and El-Geneidy [3]

$14^{\text {th }}$ LACCEI International Multi-Conference for Engineering, Education, and Technology: "Engineering Innovations for Global Sustainability", 20-22 July 2016, San José, Costa Rica. 
which consists of a four-step process for deciding which stops to consolidate along a bus route. The results are then compared against each other in order to identify any similarities as well as discrepancies.

\section{A. Benefit-Cost Ratio Methodology}

The first part of the methodology consists of calculating a benefit-cost ratio. The result will indicate if a bus stop should be eliminated or not. The formula used to compute the benefit-cost ratio is shown in (1).

Benefit to cost ratio $=\boldsymbol{B} / \boldsymbol{C}$

Where:

$\boldsymbol{B}=$ total benefit for the user of removing a bus stop and

$\boldsymbol{C}=$ total cost for the user of removing a bus stop.

The total benefit $\boldsymbol{B}$ is calculated using (2),

$$
\boldsymbol{B}=\boldsymbol{P}_{r} * \boldsymbol{T}_{r}
$$

Where:

$\boldsymbol{P}_{\boldsymbol{r}}=$ number of passengers riding trough and

$\boldsymbol{T}_{\boldsymbol{r}}=$ additional riding time associated with the stop, seconds.

Equation (2) shows that the benefit $\boldsymbol{B}$ is a function of the passengers riding through the stop and the time gained from skipping the stop [8].

For the total cost $\boldsymbol{C},(3)$ is then applied.

$$
C=P_{a} * T_{a} * V_{a}
$$

Where:

$\boldsymbol{P}_{\boldsymbol{a}}=$ quantity of passengers accessing the bus stop by boarding and alighting

$\boldsymbol{T}_{a}=$ net increase in travel time per person to access remaining stops, seconds

$\boldsymbol{V}_{\boldsymbol{a}}=$ value of access time relative to riding time

Equation (3) shows that the cost $\mathrm{C}$ of removing a stop is a function of the number of passengers using the stop, increased time to access remaining stops, and ratio of the value of access time to the value of riding time [8].

The values for the variables $\boldsymbol{P}_{\boldsymbol{r}}$ and $\boldsymbol{P}_{\boldsymbol{\alpha}}$ have already been obtained by a passenger load study performed by 14 students of the UPRM. The study started at 6:00 AM and ended at 1:00 PM and took place in San Juan, PR, along MBA Route 5 from Covadonga Terminal to Iturregui Terminal. The formulas used to obtain these values are shown in (4) and (5):

$$
\begin{gathered}
\boldsymbol{P}_{\boldsymbol{r}}=\text { load arriving }- \text { alighting } \boldsymbol{o r} \\
\text { load departing }- \text { boarding }
\end{gathered}
$$

\section{And}

$$
\boldsymbol{P}_{\boldsymbol{a}}=\text { boarding }+ \text { alighting }
$$

To obtain the value of $\boldsymbol{T}_{\boldsymbol{\alpha}}$, it is necessary to find $\boldsymbol{D}_{\boldsymbol{w}}$ (the average additional walking distance to remaining stops when some stops are removed from the line) and $\boldsymbol{v}_{\boldsymbol{w}}$ (the mean walking speed of an average person, using a default value of $3.5 \mathrm{ft} / \mathrm{s}[9,10])$. Equation (6) shows how to calculate the average additional travel time by passengers $\left(\boldsymbol{T}_{\boldsymbol{a}}\right)$ within the evaluated service area of the stop when they have to access the closest remaining stop.

$$
T_{a}=D_{w} / v_{w}
$$

Equation (7) shows a weighted average of the distance to the nearest and farthest bus stop.

$$
\boldsymbol{D}_{w}=\left(\boldsymbol{D}_{n} * \boldsymbol{D}_{f}\right) /\left(\boldsymbol{D}_{n}+\boldsymbol{D}_{f}\right)
$$

Where:

$\boldsymbol{D}_{\boldsymbol{n}}=$ distance to the nearest bus stop

$\boldsymbol{D}_{\boldsymbol{f}}=$ distance to the farthest bus stop

The last two variables are the additional riding time because of the stop, $\boldsymbol{T}_{r}$, and the value of access time relative to riding time, $\boldsymbol{V}_{\boldsymbol{a}}$. The additional-ride-time variable has a range of values between 10 and 20 seconds, choosing a midrange of 15 seconds to describe the time that a bus may save for skipping a stop. This is the value generally used by transit planners. The value-of-access-time variable is a factor usually chosen to be 2 [8]. This value corresponds to the behavior of the users of giving twice the value of walking and/or waiting time in a bus stop compared to in-vehicle time.

After all the variables and formulas are established, the next step is to create an Excel spreadsheet to calculate the benefit-cost ratio for each of the bus stops on MBA Route 5 and, according to the value for each, decide which bus stop is a candidate to be removed.

\section{B. Four-step Process for Bus Stop Consolidation}

Stewart and El-Geneidy [3] developed a methodology which consisted of a five-step process for determining if bus stop consolidation is recommended for the improvement of a bus route. The five steps consisted of the following: 1) determine the catchment area of each bus stop; 2) determine the class (or importance) of each bus stop; 3 ) decide which stops should be removed by looking for overlaps in catchment area and bus stop classes; 4) calculate the savings of removing the selected bus stops; and 5) determine the impact on passengers. However, since the last step of this methodology was beyond the scope of the present study, only the first foursteps are applied to the data.

The first step is to determine the catchment area of each stop. The authors established that the walking distance that a user is willing to walk should not be considered as a fixed distance for every bus stop, but as an individual or variable distance. This is because every bus stop has a different way of access that depends on several factors, such as: accessibility by sidewalk, population around the bus stops, intersections near

$14^{\text {th }}$ LACCEI International Multi-Conference for Engineering, Education, and Technology: "Engineering Innovations for Global Sustainability", 20-22 July 2016, San José, Costa Rica. 
the bus stops, nearest bus stop to downtown, and waiting time at the stop. For this study, a 400 meter radius was established as the catchment area around every bus stop in Route 5 .

In the second step, the main goal is to define the importance of each bus stop by sorting them in different classes. These classes are calculated using four factors: the needs of people with reduced mobility, transit connections, passenger activity, and whether the stop is the first or last stop on the route. The explanation of these four factors is as follow:

- Bus stops that serve people with reduced mobility should have priority above all others, because the impact of removing a bus stop will be greater for them than all the other users. Therefore, health care centers, senior residences, and hospitals that are inside the calculated catchment area of each stop have to be identified. In addition, it was verified that there are direct accesses from these locations to the bus stops inside the catchment area.

- In order to keep providing connectivity to any major transit line, it is necessary to assure that bus stops that serve any major transit connection should not be considered for removal. For this project, a major transit connection is defined as a connection to any station to the Tren Urbano and Metro Bus within the catchment area.

- It is important to know which bus stops have a high volume of passenger activity, but it is also important to know the variability of this activity. For that reason, a passenger activity ("pax") quality variable is used to distinguish stops with high pax and low variation from those with low pax and high variation. Equation (8) shows how to calculate the pax quality variable.

\section{PaxQuality $=(\text { Average Pax })^{2} /$ Standard Deviation}

- It is assumed that the first and last stops were located for strategic reasons related to the layover of the bus drivers.

The four factors that were explained are used to create a bus stop class that describes bus stop importance. All the stops will be categorized in six classes from A to F, with A being the most important and $\mathrm{F}$ being the least important. The criteria for each class are as follows:

Class A: Serves reduced-mobility facilities or connects to the metro, train or to major buses (frequent/express/shuttle) or is a first or last stop.

Class B: Fourth (top) quartile of pax quality.

Class C: Connects to regular bus network.

Class D: Third quartile of pax quality.

Class E: Second quartile of pax quality.

Class F: All other stops.
The third step consisted of developing a simple removal score. Bus stops with a removal score greater than zero were considered for removal and, logically, the higher the score, the greater chance of being removed. Two others factors were taken into account for a final decision: twin stops and consecutive stops.

Twin stops are defined as those stops that share the same intersection. The rule with twin stops is that both of them must be considered to be removed in order to actually be removed. In other words, if only one of the twin stops is chosen to be removed, then both of them will be kept.

Consecutive stops should not be removed to avoid creating an excessive distance between stops. If consecutives stops obtained a removal score, the even or odd stops were considered to be removed (and that depended on which one had the higher average removal score). The following process describes the required steps to give a removal score to bus stops:

1. Give each bus stop in the system an initial removal score of 0.

2. For route $\mathbf{R}$, for each direction $\mathbf{D}$ in $\mathbf{R}$, and for each stop $\mathbf{S}$ along $\mathbf{D}$ :

a. Find the stops on route $\mathbf{R}$ in direction $\mathbf{D}$ that fall within S's catchment area.

b. Find the most important stop before and after $\mathbf{S}$ within the catchment area; importance is determined first by class and second by pax quality.

c. If there are other stops within S's catchment, and if they are of lower importance than $\mathbf{S}$, and if they are not Class $\mathbf{A}$ stops, add one point to their removal scores.

3. For each stop $\mathbf{S}$ with a removal score of at least 1:

a. If $\mathbf{S}$ has a twin stop, and the twin of $\mathbf{S}$ has a removal score greater than zero, mark $\mathbf{S}$ and its twin under consideration.

b. If $\mathbf{S}$ has no twin stop, mark it as under consideration.

4. For each stop $\mathbf{S}$ under consideration that is not beside other stops under consideration: Remove $\mathbf{S}$

5. For all the groups of consecutive stops on a route that are under consideration:

a. Calculate the average removal score of the odd and even bus stops.

b. If the odd-numbered stops have a higher average score, remove them, and vice versa. Break ties on average pax quality.

The fourth and last step was to calculate the travel time savings resulting from the removal of the stops selected. This is possible by using schedule data. The six (6) steps required to calculate the total travel time savings as a result of bus stop removal are show below:

1. Calculate the number of buses.

2. Calculate the average cycle time.

$14^{\text {th }}$ LACCEI International Multi-Conference for Engineering, Education, and Technology: "Engineering Innovations for Global Sustainability”, 20-22 July 2016, San José, Costa Rica. 
3. Calculate the average headway by dividing the average cycle time by the current number of buses.

4. Determine the time savings expected from removing the selected stops; the average time saved by removing one stop is approximately 12 seconds.

5. Calculate the new cycle time by subtracting the total time savings from the cycle time.

6. Calculate the new headway by dividing the new cycle time by the current number of buses.

\section{ANALYSIS AND RESULTS}

\section{A. Passenger Load Study}

In order to apply both of the methodologies to perform all the analyses, it was necessary to perform a boarding and alighting analysis to MBA Route 5. The public agency does not have any historic information about the daily ridership. For that reason, a study of boarding and alighting was performed with a team of graduate students from 6:30am to 1:00pm, on a representative Wednesday. As a result of the passenger load study over 120 bus stops in the two-way trip were evaluated.

\section{B. Benefit-Cost Ratio}

The benefit of removing a bus stop is a function of the quantity of passengers that are riding through two bus stops and the travel time savings associated with those riders as a result of the removal of the bus stop. If a bus stop is removed, there is less time spent in the boarding and alighting of the users at a bus stop, and it results in savings in the cycle time of a route. The cost is a function of how many users are actually accessing the bus stops and how inconvenient it is to walk to the next bus stop once a stop is removed. After computing the values of the benefit and cost following every step of the methodology, the value of the benefit-cost ratio is calculated for each bus stop. Fig. 2 shows a plan view of bus stops to be removed from MBA Route 5 running eastbound as a result of this step.

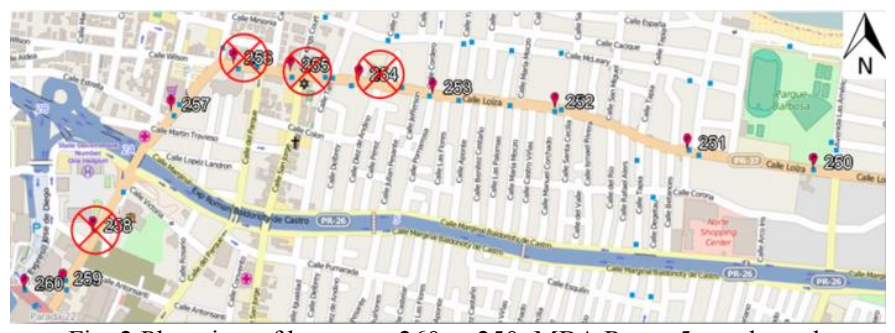

Fig. 2 Plan view of bus stops 260 to 250, MBA Route 5, eastbound.

A problem arises when two or more consecutive bus stops have a benefit-cost ratio greater than one, because it would cause a greater distance between the remaining stops. To address this issue, the average benefit-cost ratio for even and odd bus stops was calculated, specifically all the ratios greater than 1. Then, the even or odd groups of bus stops that have the greater average benefit-cost ratio were selected to be removed, as shown in Table 1. At the end of this process, 28 bus stops out of 98 were selected to be eliminated. The reduction in the number of bus stops represents $28 \%$ of the total bus stops along Route 5.

TABLE 1

Decision MaKing Process Associated with OdD or Even CONSECUTIVE Bus STOPS

\begin{tabular}{|c|c|c|c|}
\hline Stop ID & B/C & $\begin{array}{c}\text { Avg. Even } \\
\text { Stops }\end{array}$ & Avg. Odd Stops \\
\hline 254 & 1.4 & \multirow{2}{*}{1.4} & 2.8 \\
\hline 255 & 2.8 & & \\
\hline 256 & 1.4 & & \\
\hline
\end{tabular}

\section{Four-step Process}

This process shows more sensibility with respect to transit users with reduced mobility and the need to reach health care services and hospitals. This method is aimed at deciding which bus stops should be removed based on their social importance.

For the catchment area, a buffer of 400 meters in both directions around every bus stop on Route 5 was established to represent a standard walking distance in which people are willing to walk to a transit stop [11]. Fig. 3 shows proximity of all bus stops, specifically the excess overlapping of catchment areas can easily be seen.

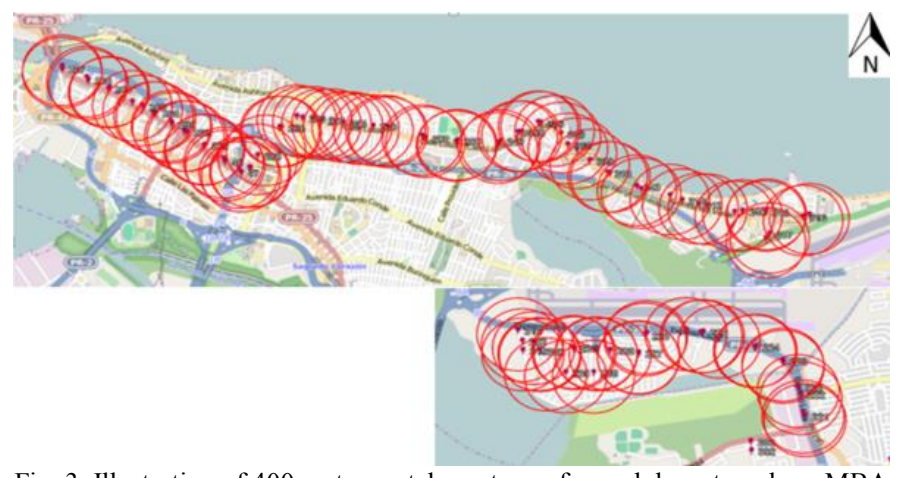

Fig. 3 Illustration of 400 meters catchment area for each bus stop along MBA Route 5.

Four factors that were considered to decide which bus stops have greater classification are:

Reduced mobility: A total of 19 hospitals, 17 health care centers and 56 nursing homes around the SJMA were identified.

Transit connection: Terminals and transfer centers of MBA were taken into account since MBA Route 5 does not have any Tren Urbano station nearby.

Passenger activity: The larger the pax quality value, the more reliable the bus stop passenger activity. Table 2 shows an example of each of the variables to calculate the pax quality.

First and last stop: It is assumed that the first and last stops were located for strategic reasons related to bus driver overlay. 
TABLE 2

PAX QUALITY FOR EACH BUS STOP

\begin{tabular}{|c|c|c|c|c|}
\hline $\begin{array}{c}\text { Bus Stop } \\
\text { ID }\end{array}$ & $\boldsymbol{\mu}$ & $\boldsymbol{\sigma}$ & $\boldsymbol{\mu} / \boldsymbol{\sigma}$ & PaxQuality \\
\hline Terminal & 6.88 & 3.68 & 0.53 & 12.8 \\
\hline 279 & 1.13 & 1.12 & 1.0 & 1.12 \\
\hline 280 & .025 & 0.46 & 1.85 & 0.13 \\
\hline
\end{tabular}

When all four factors were determined, each bus stop was classified. Table 3 shows the classification distribution of the 98 bus stops on MBA Route 5 .

TABLE 3

DistRIBUTION OF BUS STOP ClASSES

\begin{tabular}{|c|l|c|c|}
\hline Class & \multicolumn{1}{|c|}{ Criteria } & Qty. & Percent \\
\hline A & $\begin{array}{l}\text { Bus stops that serve transit users with } \\
\text { reduced mobility or that serves major transit } \\
\text { connections or first and last stops. }\end{array}$ & 37 & 38 \\
\hline B & Fourth (top) quartile of pax quality & 8 & 8 \\
\hline $\mathbf{C}$ & $\begin{array}{l}\text { Bus stops that serves terminals and/or } \\
\text { transfer centers of the MBA }\end{array}$ & 2 & 2 \\
\hline D & Third quartile of pax quality & 17 & 17 \\
\hline $\mathbf{E}$ & Second quartile of pax quality & 16 & 16 \\
\hline F & All other stops & 18 & 18 \\
\hline & Total & $\mathbf{9 8}$ & $\mathbf{1 0 0}$ \\
\hline
\end{tabular}

Table 4 shows the process of granting the removal score for every bus stop. For example, bus stop 230 has two stops before and five stops after, as shown in Fig. 4. The bus stops before stop 230 (229 and 228) have class D and E, respectively. However, bus stop 228 has a lower pax quality, thus is granted one point to the removal score. The bus stops after stop $230(231,234$, and 235) have a classification of F, and stop 236 has a D classification. In this case, the bus stop with the highest classification (bus stop 236, class D) does not have a removal score point, but of the other bus stops remaining, bus stop 231 has an F classification and the lowest pax quality, thus is granted one point to the removal score.

TABLE 4

PROCESS OF GRANTING REMOVAL SCORE TO THE BUS StOPS

\begin{tabular}{|c|c|c|c|c|c|}
\hline $\begin{array}{c}\text { Bus Stop } \\
\text { ID }\end{array}$ & Class & PaxQuality & $\begin{array}{c}\text { Stops } \\
\text { Before }\end{array}$ & $\begin{array}{c}\text { Stops } \\
\text { After }\end{array}$ & $\begin{array}{c}\text { Removal } \\
\text { Score }\end{array}$ \\
\hline 225 & E & 0.26 & 0 & 0 & - \\
\hline 226 & D & 0.63 & 1 & 2 & - \\
\hline 227 & D & 0.53 & 1 & 1 & 1 \\
\hline 228 & E & 0.44 & 2 & 3 & 2 \\
\hline 229 & D & 0.60 & 1 & 3 & - \\
\hline 230 & F & 0.15 & 2 & 5 & 4 \\
\hline 231 & F & 0.06 & 1 & 4 & 6 \\
\hline 232 & D & 0.60 & 1 & 2 & - \\
\hline 233 & F & 0.12 & 3 & 1 & 6 \\
\hline 234 & F & 0.17 & 4 & 1 & 4 \\
\hline 235 & F & 0.19 & 4 & 1 & 3 \\
\hline 236 & D & 0.50 & 4 & 0 & - \\
\hline 237 & F & 0.07 & 0 & 2 & - \\
\hline
\end{tabular}

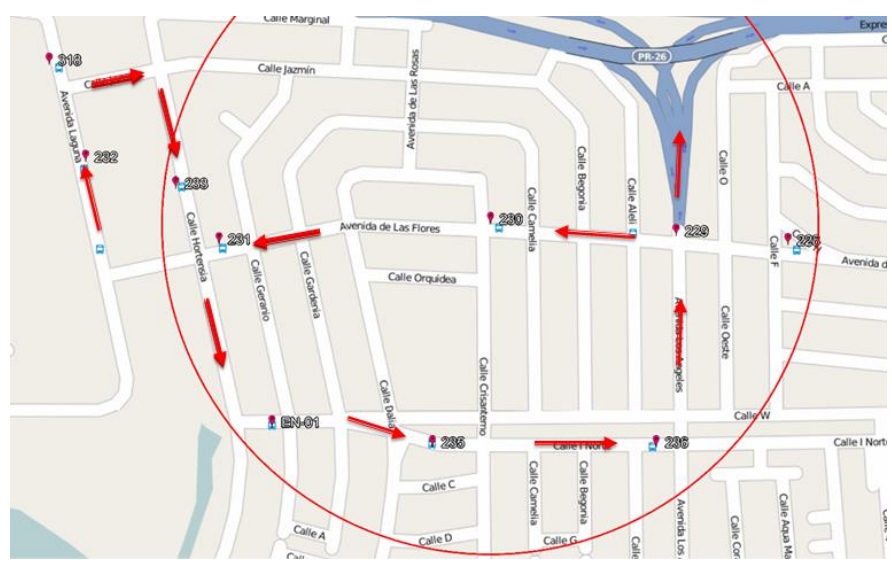

Fig. 4 Bus stops within the catchment area of the bus stop 230

An interesting result of the removal score process is the realization that, in many cases, several consecutive bus stops were closely located and obtained a classification of A. The reason for these results is several bus stops serving the same hospital, health care center, or nursing home, giving the bus stops a high classification. Fig. 5 shows how five bus stops (297 to 301) are serving the same nursing home named Hogar Elvira along Route 5. For those bus stops, a reevaluation of the class was performed which consisted of identifying which bus stop is actually serving the reduced mobility center or, at least, which of those has the greatest probability. Because of this, the walking distance of each bus stop to the reduced mobility center was measured, and the nearest bus stop that serves that place is chosen to be the Class A bus stop, as shown in Table 5. The rest of the bus stops ended with a classification dependent on the pax quality or whether or not it served a major transit facility.

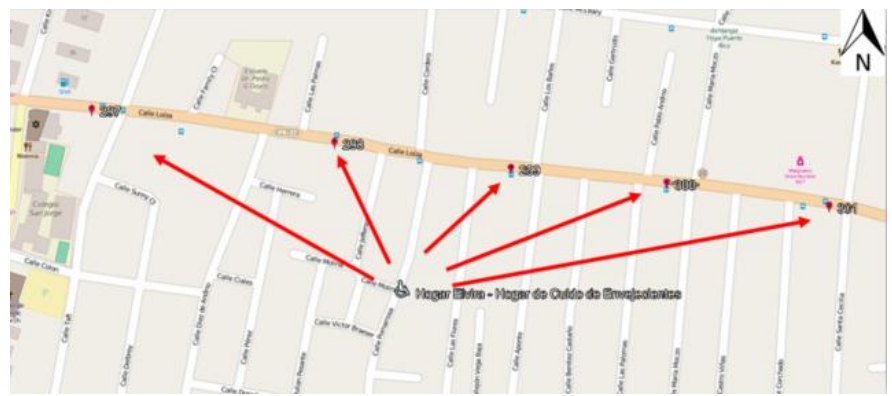

Fig. 5 Consecutive class A bus stops 297 to 301 that serve the same nursing home, Hogar Elvira

TABLE 5

REEVALUATION PROCESS APPLIED TO BUS STOPS 297 TO 301.

\begin{tabular}{|c|c|c|c|c|}
\hline $\begin{array}{c}\text { Reduced } \\
\text { Mobility Center }\end{array}$ & Stop ID & Class & $\begin{array}{c}\text { Pax } \\
\text { Quality }\end{array}$ & $\begin{array}{c}\text { Walking Distance } \\
\text { ft (m) }\end{array}$ \\
\hline \multirow{4}{*}{ Home Elvira } & 297 & A & 0.59 & $1437(438)$ \\
\cline { 2 - 5 } & 298 & A & 0.58 & $703(214)$ \\
\cline { 2 - 5 } & 299 & A & 0.66 & $657(200)$ \\
\cline { 2 - 5 } & 300 & A & 0.85 & $1130(345)$ \\
\cline { 2 - 5 } & 301 & A & 0.58 & $1616(493)$ \\
\hline
\end{tabular}

$14^{\text {th }}$ LACCEI International Multi-Conference for Engineering, Education, and Technology: "Engineering Innovations for Global Sustainability”, 20-22 July 2016, San José, Costa Rica. 
Table 6 shows the different classes of bus stops that changed due to the reevaluation. In the end, there were 16 bus stops that were selected to be removed by this procedure.

TABLE 6

NEW Distribution of Bus STOP Classes AFTER REEVALUATION OF CONSECUTIVE Class A Bus STOPS

\begin{tabular}{|c|l|c|c|}
\hline Class & \multicolumn{1}{|c|}{ Criteria } & Qty. & Percent \\
\hline A & $\begin{array}{l}\text { Bus stops that serve people with reduced } \\
\text { mobility or that serves major transit } \\
\text { connections or first and last stops }\end{array}$ & 25 & $26 \%$ \\
\hline B & Fourth (top) quartile of pax quality & 14 & $14 \%$ \\
\hline C & $\begin{array}{l}\text { Bus stops that serve terminals and/or } \\
\text { transfer centers of the MBA }\end{array}$ & 1 & $1 \%$ \\
\hline D & Third quartile of pax quality & 24 & $24 \%$ \\
\hline E & Second quartile of pax quality & 16 & $16 \%$ \\
\hline F & All other stops & 18 & $18 \%$ \\
\hline & Total & $\mathbf{9 8}$ & $\mathbf{1 0 0 \%}$ \\
\hline
\end{tabular}

The last step of the process was to calculate the savings of removing the selected bus stops. These savings are a result of the time earned from the removal of the bus stops. The time saved from removing a bus stop is set to 12 seconds, only if the pax quality is higher than 1 . If the pax quality is less than 1 , the savings will be 12 second multiplied by the pax quality. For example, in Table 7 bus stop 228 has a pax quality of 0.75 , thus the saving time for removing this bus stop is $0.75 \times 12$ seconds, resulting in a saving time of 9 seconds. The logic behind these steps is that the time saved for the removal of a bus stop that has little or non-ridership should not be equal to that of a highly utilized bus stop.

TABLE 7

Travel Time Savings for EACH Bus Stop SElected to Be Removed IN THE FOUR-STEP PROCEDURE

\begin{tabular}{|c|c|c|c|}
\hline Bus Stop ID & Class & Pax Quality & Travel Time (sec) \\
\hline 228 & E & 0.75 & 9.0 \\
\hline 231 & F & 0.04 & 0.5 \\
\hline 233 & F & 0.11 & 1.3 \\
\hline 235 & F & 0.27 & 3.2 \\
\hline 239 & D & 2.94 & 12.0 \\
\hline
\end{tabular}

To calculate how much time is saved from the cycle time of MBA Route 5, it was necessary to know the actual cycle time and how many buses serve that route. The runtime of each cycle was calculated as well as the layover for each bus, resulting in the total cycle time. Table 8 shows the results of travel time savings. The removal of 16 bus stops represents a runtime savings of $2.2 \%$ in total cycle time.
TABLE 8

CALCULATION PROCESS OF THE SAVINGS FROM REMOVING A BUS STOP

\begin{tabular}{|l|c|c|}
\hline Variable & Units & Value \\
\hline Buses & each & 4 \\
\hline Average Cycle Time & $\min$ & 84.23 \\
\hline Average Headway & $\min$ & 21.06 \\
\hline Time Savings from Removing Stops & $\mathrm{sec}$ & 109.92 \\
\hline New Cycle Time & $\min$ & 82.40 \\
\hline New Headway & $\min$ & 20.60 \\
\hline
\end{tabular}

\section{Iteration of Both Methods}

An additional step was performed after the implementation of the benefit-cost ratio and the four-step process method. This extra step was applied as an iteration of both methodologies and the main idea lies in two reasons. The first reason is to verify the veracity of both methods. The second reason is to re-evaluate the bus stops with a benefitcost ratio bigger than 1 , as well as stops with a potential removal score from the four-step process, but not selected to be removed.

In the benefit cost ratio method, the iteration began applying the method with the new set of bus stops. This new set of bus stops had several new distances between them due to the elimination of 28 bus stops. After the iteration, every bus stop obtained a new benefit-cost ratio, several of them with ratios greater than 1 , which were analyzed individually.

Although the removal of consecutive bus stops was not allowed in this process, it was worth it to check what was really happening in the second iteration. The result was that several consecutive bus stops still had benefit-cost ratios greater than 1 . The proposed solution was to calculate the distance between the remaining bus stops, if any of the consecutive bus stops were selected to be removed and verify if they met the requirement of the 400 meters catchment. If those bus stops met the requirement, the removal of the bus stop was not considered to be a problem; however, if they did not meet the requirement, they should not be considered to be removed. After applying this analysis with each bus stop, the final results of the benefit-cost ratio method recommended a total of 32 bus stops to be removed. This represents four more bus stops than the initial 28 stops that were to be removed due to the first iteration.

The iteration of the four-step process was similar to the benefit-cost ratio process. The process of the removal score part was repeated with a new set of bus stops and several new distances between some stops. There were four additional stops selected for removal by the second iteration of the fourstep process, increasing the number of removed bus stops from 16 to 20 . The distance between the remaining bus stops, after those four stops were removed, slightly exceeded the 400 meter requirement. The new travel time savings from removing all proposed bus stops results in an increase of $2.5 \%$ in cycle time.

$14^{\text {th }}$ LACCEI International Multi-Conference for Engineering, Education, and Technology: "Engineering Innovations for Global Sustainability”, 20-22 July 2016, San José, Costa Rica. 


\section{E. Results}

The results of the application of these two methodologies are very interesting and very simple. The benefit-cost ratio method indicates a higher number of bus stops to be removed compared to the four-step process. The final results that each method provides are summarized as follows:

1. Benefit-Cost ratio methodology suggested 32 bus stops for removal.

2. Four-step process methodology suggested 20 bus stops for removal.

3. Both methodologies suggest the same 11 bus stops for removal.

4. Running times improved $2.5 \%$ due to the bus stop removal of the four-step methodology.

\section{F. Combination of Methods}

In order to provide clear and confident results of which bus stops should finally be selected to be removed, a combination of both methodologies is provided. The main idea of this combination is to identify the bus stops that the fourstep process considers as Class A and choose them as not-forremoval. Then, the benefit-cost ratio method is used to complement the four-step process to combine the final results of both methods. Basically, the four-step process helps to filter the results from the benefit-cost ratio, making sure that the bus stops with social importance are not removed by the benefitcost ratio method. Table 9 shows the final bus stops to be removed by both methodologies. The total number of bus stops to be removed is 36 , representing almost $37 \%$ of all the bus stops in Route 5 of the MBA.

\section{CONCLUSIONS}

The main goal of this study was reached by demonstrating two standardized procedures that identify and recommend the bus stops that should be removed. Both procedures take into account the ridership of every bus stop, as well as the land use around them. The benefit-cost ratio and the four-step process recommend which bus stops have to be eliminated, but the application of the engineering judgment is still necessary to provide a final answer. The final results from both methodologies may not be the same; therefore, someone with transit or planning background should have the final say in which bus stops should be eliminated. To address this issue, a combination of both methodologies was applied in which, basically, the four-step process helps to filter the results from the benefit-cost ratio methodology, making sure that bus stops with social importance are not removed by the benefit-cost ratio method. Therefore, it is concluded that a combination of both methods is the best tool for the evaluation of bus stops.

It is vital to recognize the importance and relevance of each bus stop because every one of them might have a reason, with or without planning, for their location. If any of these bus stops have to be removed, it is necessary to conduct surveys and gather deeper information about the activity around them and understand the purpose of their locations before doing so.

TABLE 9

Final Bus Stops to be ReMOVED by Both Methodologies

\begin{tabular}{|c|c|c|c|}
\hline $\begin{array}{c}\text { Bus Stop ID } \\
(\mathrm{WB})\end{array}$ & $\begin{array}{c}\text { Final Bus Stop to } \\
\text { Remove }\end{array}$ & $\begin{array}{l}\text { Bus Stop ID } \\
\text { (EB) }\end{array}$ & $\begin{array}{c}\text { Final Bus Stop } \\
\text { to Remove }\end{array}$ \\
\hline 287 & - & 221 & $\mathrm{~A}$ \\
\hline 288 & - & 222 & $\mathrm{x}$ \\
\hline 289 & $\mathrm{x}$ & 223 & - \\
\hline 290 & - & 224 & $\mathrm{x}$ \\
\hline 291 & - & 225 & - \\
\hline 292 & $\underline{x}$ & 226 & - \\
\hline 44 & - & 227 & - \\
\hline 45 & $\mathrm{~A}$ & 228 & $\underline{\mathrm{x}}$ \\
\hline 46 & A & 229 & - \\
\hline 47 & $\mathrm{~A}$ & 230 & $\mathrm{xx}$ \\
\hline 293 & $\mathrm{XX}$ & 231 & $\underline{\mathrm{X}}$ \\
\hline 294 & A & 232 & - \\
\hline 295 & $\mathrm{~A}$ & 233 & $\mathrm{XX}$ \\
\hline 296 & - & 234 & $\underline{x}$ \\
\hline 297 & $\mathrm{x}$ & 235 & $\mathrm{XX}$ \\
\hline 298 & $\underline{\mathrm{x}}$ & 236 & - \\
\hline 299 & $\bar{A}$ & 237 & $\mathrm{x}$ \\
\hline 300 & $\mathrm{~A}$ & 238 & - \\
\hline 301 & $\mathrm{~A}$ & 239 & $x x$ \\
\hline 302 & - & 240 & - \\
\hline 303 & $\mathrm{~A}$ & 241 & - \\
\hline 304 & - & 242 & $\mathrm{x}$ \\
\hline 305 & - & 243 & - \\
\hline 306 & $\mathrm{x}$ & 244 & A \\
\hline 307 & $\underline{\mathrm{x}}$ & 245 & $\mathrm{~A}$ \\
\hline 308 & - & 246 & $\mathrm{X}$ \\
\hline 309 & $\overline{\mathrm{A}}$ & 247 & - \\
\hline 310 & $\bar{A}$ & 248 & $\mathrm{x}$ \\
\hline 311 & $\mathrm{x}$ & 249 & - \\
\hline 312 & - & 250 & $\mathrm{~A}$ \\
\hline 313 & $x$ & 251 & - \\
\hline 314 & - & 252 & A \\
\hline 315 & $\mathrm{xx}$ & 253 & $\bar{A}$ \\
\hline 316 & - & 254 & $\underline{\underline{x}}$ \\
\hline 317 & $\underline{\mathrm{X}}$ & 255 & $\underline{\underline{x}}$ \\
\hline 318 & - & 256 & $\mathrm{~A}$ \\
\hline 319 & $\underline{x}$ & 257 & $\mathrm{~A}$ \\
\hline 320 & - & 258 & A \\
\hline 321 & - & 259 & A \\
\hline 322 & - & 260 & $\mathrm{xx}$ \\
\hline 323 & $\mathrm{x}$ & 261 & A \\
\hline 324 & - & 262 & - \\
\hline 325 & - & 263 & $\mathrm{~A}$ \\
\hline 326 & $\mathrm{x}$ & 264 & $\mathrm{X}$ \\
\hline 327 & $\mathrm{xx}$ & 265 & $\mathrm{XX}$ \\
\hline 328 & $\underline{\mathrm{x}}$ & 266 & $\mathrm{~A}$ \\
\hline 329 & - & 267 & $\mathrm{x}$ \\
\hline 330 & $\mathrm{x}$ & 268 & A \\
\hline 331 & - & 269 & - \\
\hline Total & 17 & Total & 19 \\
\hline \multicolumn{4}{|c|}{$\begin{array}{l}\mathrm{x}-\text { Removed by the first methodology (B/C Ratio) } \\
\mathrm{xx}-\text { Removed by the second methodology (four-step process) } \\
\underline{\underline{x}}-\text { Removed by both methodologies } \\
\mathrm{A} \\
\text { - Not for removal }\end{array}$} \\
\hline
\end{tabular}


A great enhancement will be if a more comprehensive passenger load study, or automated counting data, was available. With such information the applications of both methods would be more accurate and could be applied to others MBA routes as well.

\section{RECOMMENDATIONS}

For future studies it is recommended to perform a third methodology to identify where the bus stops really should be along MBA Route 5. A design from scratch of the locations of bus stops and a study of all the areas along MBA Route 5 would be ideal. It is necessary to study the population, activity centers, and origin-destination places to design a new set of bus stops that serve, not only the actual needs, but the future needs of the users as well. The final design could be compared with the actual bus stop locations and, along with the benefitcost ratio and the four-step processes, could be used to more accurately determine which bus stops are really important and which ones should be removed, as well as helping to identify which method is more appropriate in selecting the stops to be removed.

Another recommendation is to gather additional information about the transit users who use MBA Route 5 in regards to the actual decisions of which bus stops they are currently using. In addition, the survey can gather information related to their willingness to walk to other locations in the case of removing some bus stops. The results of this survey could shed additional information to improve Step 3 of the four-step process, specifically the reevaluation of Class A bus stops.

Lastly, it is recommended to perform a sensitivity analysis for the results of the benefit-cost ratio. This method has several variables that have a range of values; for this study, a midrange value was selected. A sensitivity analysis could be useful to analyze if a change in the results occurs with the use of different input values.

\section{REFERENCES}

[1] Figueroa, A., "College of Engineering and Surveying of Puerto Rico: Design, Location and Inspection of Bus Stops". San Juan, PR, 2013.

[2] P. Furth and A. Rahbee, "Optimal bus stop spacing trough dynamic programming and geographic modeling," in Transportation Research Record, 2000, pp. 15-22.

[3] C. Stewart and A. El-Geneidy, "Don't stop yet! A simple, effective, and socially responsible approach to bus-stop consolidation," in Transportation Research Board 94 ${ }^{\text {th }}$ Annual Meeting, 2014, pp. 15-22.

[4] A. El-Geneidy, T. Kimpel, and J. Strathman, "Empirical Analysis of the Effects of Bus Stops Consolidation on Passenger Activity and Transit Operations" College of Urban and Public Affairs

[5] H. Li, and R. Bertini, "Assessment of an Optimal Bus Stop Spacing Model Using High Resolution Archived Stop-Level Data" in Transportation Research Record: Journal of Transportation Research Board, 2009, pp. 24-32

[6] KFH Group, Inc., "Guidelines for the Design and Placement of Transit Stops for the Washington Metropolitan Area Transit Authority" Maryland: Washington Metropolitan Area Transit Authority, 2009

[7] J. Moura, B. Alonso, A. Ibeas and F. Ruisánchez, "A Two-Stage Urban Bus Stop Location Model" in Springer Science+Business Media, 2011
[8] Z. Wagner and R. Bertini, "Benefit-Cost Evaluation Method fo Transit Stop Removal" in Transportation Research Record, 2014, pp. 59-64.

[9] Federal Highway Administration, "Manual on Uniform Traffic Control Devices (MUTCD)" Washington, D.C. 2009.

[10] TCRP Report 112/NCHRP Report 562, "Improving Pedestrian Safety at Unsignalized Crossings" Transportation Research Research Board, Washington, D.C., 2006.

[11] J. Walker, "Human Transit: Basics - Walking distance to transit", retrived from professional blog of Public Transit Planning: http://www.humantransit.org/2011/04/basics-walking-distance-totransit.html

14 ${ }^{\text {th }}$ LACCEI International Multi-Conference for Engineering, Education, and Technology: "Engineering Innovations for 